\title{
Students' Perceived Benefits of Integrating a BSc in Health Sciences within a Medical Degree at Sultan Qaboos University
}

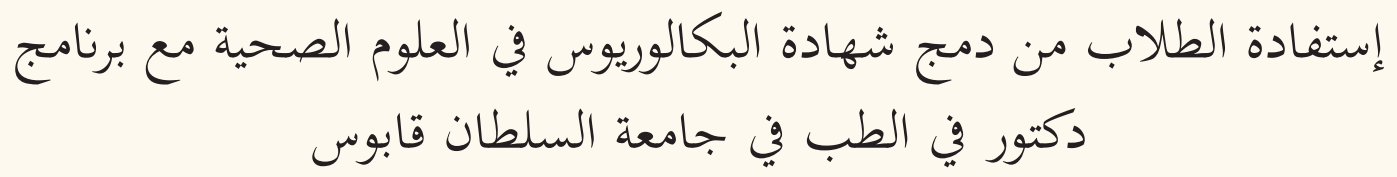

$$
\text { محمد رشيد بولعسل، إكرام برني، نادية الوردية، عمر حبال، عمر الرواس }
$$

ABSTRACT: Objectives: After completing the pre-clinical phase of a Doctor of Medicine (MD) curriculum, undergraduate medical students may choose to add a Bachelor of Science (BSc) degree in health sciences to their MD degree. Limited data exists on the motives behind students' decisions to undertake such intercalated degrees. Hence, this study aimed to identify the factors that influence students in making this choice. Methods: Undergraduate students who chose the research-based academic track of the intercalated phase of the BSc programme at the College of Medicine and Health Sciences, Sultan Qaboos University, Muscat, Oman, between 2014-2018 were enrolled. A standardised and validated self-explanatory questionnaire examining motivations to join the intercalated phase was administered to all students in the first week of enrolment. Results: Over a five-year period, out of 557 eligible students, 18 (3\%) were enrolled in the intercalated phase and all completed the questionnaire. The mean age was $22 \pm 1.5$ years and the majority (83\%) were female. Out of the 18 students, 10 (55\%) had taken the university's foundation programme. A total of $45 \%$ of students chose to intercalate out of their own interest, regardless of career ambitions. The main reasons to intercalate were an opportunity to enhance research experience, alignment with long-term career goals and a chance to publish in indexed journals. Conclusion: Despite the benefits of obtaining an additional degree, a relatively small proportion of MD students were attracted to the intercalated phase. A better presentation of the BSc degree is needed to help students make a more informed decision.

Keywords: Medical Education; Undergraduate Medical Education; Career Choice; Curriculum; Oman.

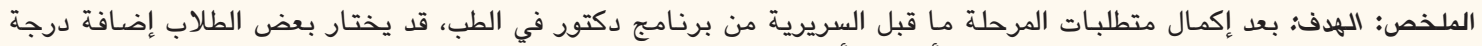

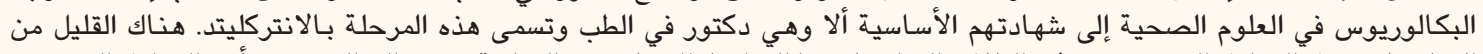

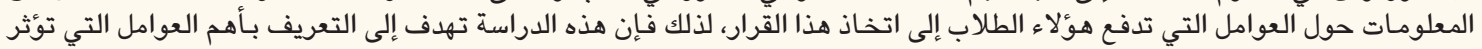

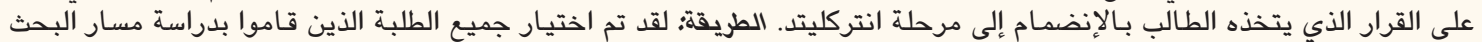

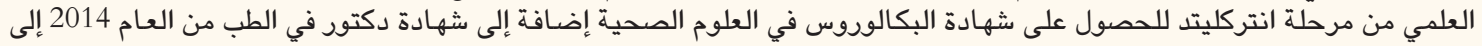

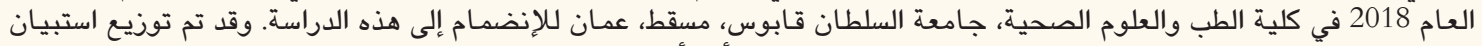

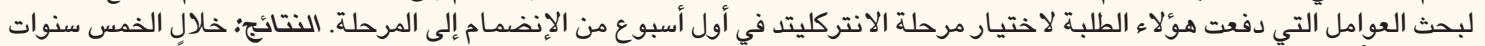

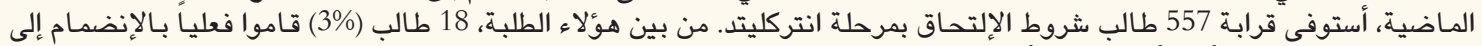

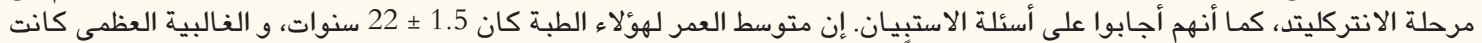

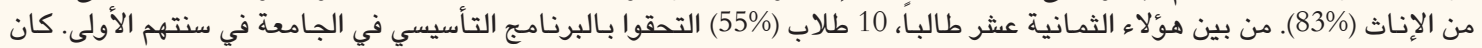

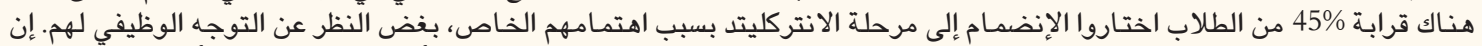

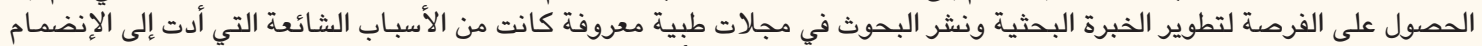

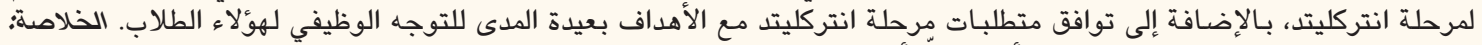

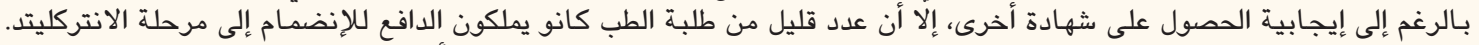

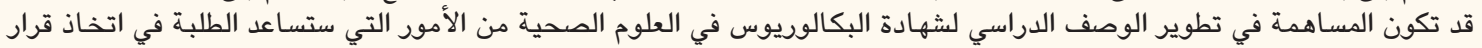
الإنضمام إلى مرحلة أنتركليتد.

$$
\text { الكلمات المفتاحية: التعليم الطبي؛ التعليم الطبي الجامعي؛ اختيار المهنة؛ البرنامج؛ عمان. }
$$

\section{Advances In KNOWLedge}

To the best of the authors' knowledge, this study was the first conducted at Sultan Qaboos University (SQU) to identify the reasons influencing medical undergraduate students' decisions to undertake the intercalated phase of the Doctor of Medicine curriculum.

Medical undergraduate students who joined the intercalated phase throughout the five-year study period demonstrated maturity and autonomy in their thinking. They undertook the Bachelor of Science (BSc) degree with a deep interest in medical research and future academic positions.
} 
Application to Patient Care

The intercalated BSc degree at SQU resulted in developing a 'cluster' of medical undergraduate students who may become clinicianacademicians capable of taking scientific discovery to the bedside to enhance patient care.

Promoting an intercalated phase is an essential step to help attract more students to applying for a BSc degree and foster the development of medical scientists in Oman.

$\mathrm{I}$ NTERCALATED DEGREES MAY BE UNDERTAKEN AS part of medical undergraduate coursework. These degrees are endowed with several advantages as they allow students to spend a year focusing on areas they particularly enjoy while they obtain an additional degree as well as skills. Pursuing an intercalated degree may also provide a competitive edge when individuals apply for programmes after graduation. Pursuing an intercalated degree can support students in enlarging their professional networks and making new friends. Such a degree also allows students to take a year off from the busy life of medical school. Additionally, medical schools, health systems and society get more well-rounded graduates who are well-versed in research skills, innovative thinking and other related areas. However, there are some disadvantages to an intercalated degree, including an extra year at the undergraduate level and additional costs. ${ }^{1-3}$ Several medical schools offer the intercalated degree as an option.

At Sultan Qaboos University (SQU), Muscat, Oman, the Doctor of Medicine (MD) degree programme has evolved to meet the varying needs of the public and align with the increasing demands of healthcare services. Indeed, the MD programme was redesigned and restructured with the end goal of shifting the curriculum from a traditional discipline-based model to an outcome-based integrated curriculum that fosters independent learning and critical thinking. The new MD curriculum was launched in 2008 at SQU's College of Medicine and Health Sciences (COMHS) with an annual intake of 130 students which included 65 males and 65 females. ${ }^{4}$ To be admitted into the $\mathrm{MD}$ programme, a minimum $\mathrm{B}+$ grade point average (GPA) in the three out of four science subjects, namely biology, chemistry, mathematics and physics, is required. Currently, all medical students are of Omani origin and the programme is provided free of cost. The curriculum consists of three phases. Phase I comprises college requirements and college and university electives and a minimum focused GPA of 2.5 is required to progress to the next phase. Phase II consists of integrated system courses, integrated modules offering opportunities for early clinical exposure and student projects spanning three semesters to introduce students to research. A cumulative GPA of $\geq 2.5$ is required at this stage to progress to Phase III which is the clinical clerkship phase. It is at this juncture that students might opt to intercalate in order to obtain a Bachelor of Science (BSc) in Health Sciences. The minimum time to complete the MD degree is six years and the maximum allowed time is nine years.

The intercalated year of study runs two parallel tracks-the hospital management/hands-on track (Track 1) and the research track (Track 2). Track 1 is limited to students who do not achieve a GPA of 2.5; they graduate from the COMHS with a BSc degree in Health Sciences after successful completion of taught courses and hands-on practice. Track 2 is offered to students who achieve a GPA $\geq 2.5$. Unlike many other medical schools where this form of intercalated year is offered to a limited number of students, such as the top 10-20\%, SQU offers this track to all students who achieve the required GPA. Students take some taught courses but spend most of their time learning research methods, carrying out a research project and finally submit a written thesis. On completion of the intercalated phase, Track 2 students enter the clinical Phase III of the MD programme for an additional three years. When completed, students are awarded two degrees - the BSc in Health Sciences and the MD.

Although some studies report that intercalated degrees may add value to undergraduate programmes, other studies have found no effect of taking an intercalated degree on academic performance among medical students. ${ }^{2,5-9}$ These conflicting results highlight the need to conduct more studies to assess whether taking an integrated degree would affect medical students' academic performance.

According to the social cognitive career theory, three main elements-self-efficacy beliefs, outcome expectations and personal goals-influence a student's decision-making around career choices; hence, these elements may play a role in choosing whether to do an intercalated degree. ${ }^{10}$ Early studies have shown that a balance between career prospects and financial challenges is the main driving force for undergraduate students when deciding whether to take an intercalated degree., ${ }^{1,3}$ However, it should be emphasised that these findings may not be applicable to other medical schools, including SQU, as Omani students pay no tuition or fees. In addition, the decision to intercalate could be influenced by several other factors such as cultural background, educational system and 
geographical variations. ${ }^{1,9}$ Thus, factors influencing choosing an intercalated degree within one country may differ from the factors in other countries even though the general features of the MD programmes may be similar. Identifying these influential factors is crucial not only to help students make an informed decision about joining the degree but also to improving teaching outcomes in general. Therefore, in order to attract more students to the intercalated phase, especially those who are genuinely interested, stakeholders need to identify the factors influencing this decision-making. To date, no studies have examined the motives influencing students' decisions to undertake an intercalated degree at SQU's COMHS. Hence, this exploratory study aimed to identify motives influencing undergraduate medical students' decisions to pursue a BSc as an intercalated degree.

\section{Methods}

This study included undergraduate medical students who had opted to take Track 2 of the intercalated phase between 2014-2018 at SQU's COMHS. In the first week of enrolment, students were invited to complete a standardised and validated self-explanatory questionnaire adapted from a previous study which examined the motivations to join intercalated medical programmes. ${ }^{1}$ To suit the SQU's intercalated degree, minor modifications were made by adding demographic items, including the participants' MD programme paths and place of residence. These added items did not affect the main content of the questionnaire. The questionnaire was administered in English and handed personally to all participants and completed manually. The paper questionnaires were then collected and data were recorded in Microsoft Excel, Version 13.0 (Microsoft Corp., Redmond, Washington, USA).

The questionnaire consisted of ten items. The first four questions asked for demographic information including gender, age, marital status and Omani governorate of residence. The next three questions were related to MD programme entry, decisionmaking around choosing the intercalated phase and career ambitions. Students were asked to select the benefits of doing the intercalated BSc degree from a list of 14 reasons and could select more than one benefit. Finally, students were asked if they thought that the intercalated degree could improve their thinking and reasoning skills as well as their academic performance, using three open-ended questions.

GraphPad Prism software, Version 5.0 (GraphPad Software, San Diego, California, USA) was used to analyse the data. Percentage, mean, standard deviation and bar graphs were used to illustrate the data. Comparisons were made using a Chi-square test with a $P$ value less than 0.05 considered statistically significant.

Students were informed that the questionnaire was completely anonymous and participation was entirely voluntary. This study was approved by the Medical Research Ethics Committee (MREC \#1883) at SQU.

\section{Results}

Over the five-year study period, a total of 607 students were enrolled in Phase II of the MD degree. Among these, 50 students were not eligible to enter the clinical Phase III of the MD programme and were advised to take Track 1 and graduate with a BSc degree in Health Sciences. The remaining students $(n=557)$ achieved a GPA $\geq 2.5$ and were eligible to progress to the clinical Phase III. Of this total, 18 students (3\%) decided to take the intercalated degree and all completed the questionnaire. Their GPAs at the end of Phase II ranged from 2.8-3.4. The mean age of the study cohort was $22 \pm 1.5$ years (range: $21-26$ years). Of the participants, 15 (83\%) were female and all students, except one, were unmarried (95\%). The students were from different parts of Oman including Muscat Governorate, which was the most common (39\%), followed by Ad-Dakhiliyah (32\%), Ad-Dhahirah (11\%), Al-Batinah (7\%), Ash-Sharqiyah (6\%) and Al-Buraymi (5\%).

The number of students who took the foundation programme was higher, but not statistically significant when compared to students who joined the MD programme directly (55\% versus $45 \% ; P=0.45$ ). More than a third of the students (33\%) indicated that they were influenced by family members to take the intercalated phase. While $45 \%$ of students said they were interested in the BSc degree on their own and that no one influenced their decision to take the intercalated phase, $22 \%$ of students indicated that others had influenced their decision to undertake the intercalated phase. Almost 39\% of students said they did not know what their career path would be. Similar proportions of students were aiming for an academic position or a hospital-based career (33\% and 28\%, respectively) [Figure 1].

All students agreed that the intercalated phase would provide experience in research. Students agreed that new skills would be learnt (78\%), their knowledge would be broadened (78\%) and that they might be able to publish (83\%). Interestingly, $78 \%$ of students indicated that the intercalated phase would 


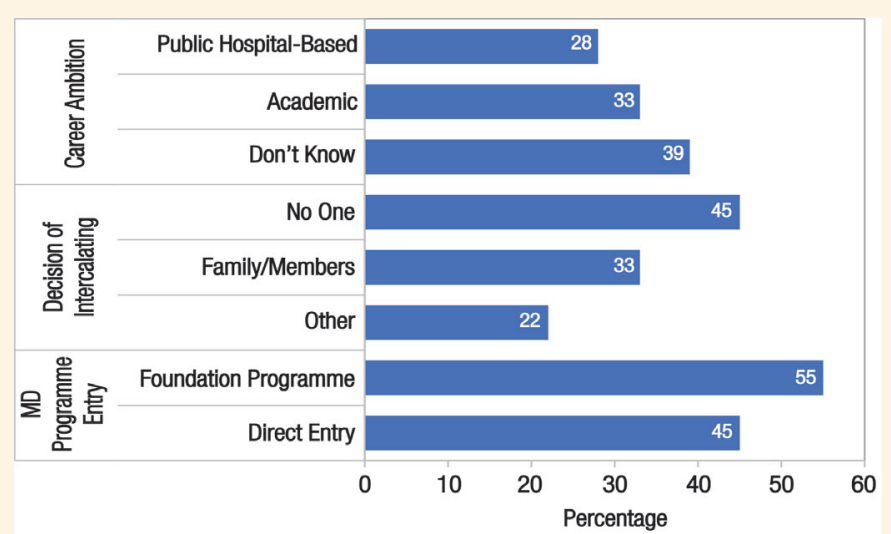

Figure 1: Characteristics of students according to Doctor of Medicine programme entry, decision to intercalate and career ambitions $(\mathrm{N}=18)$.

$M D=$ Doctor of Medicine.

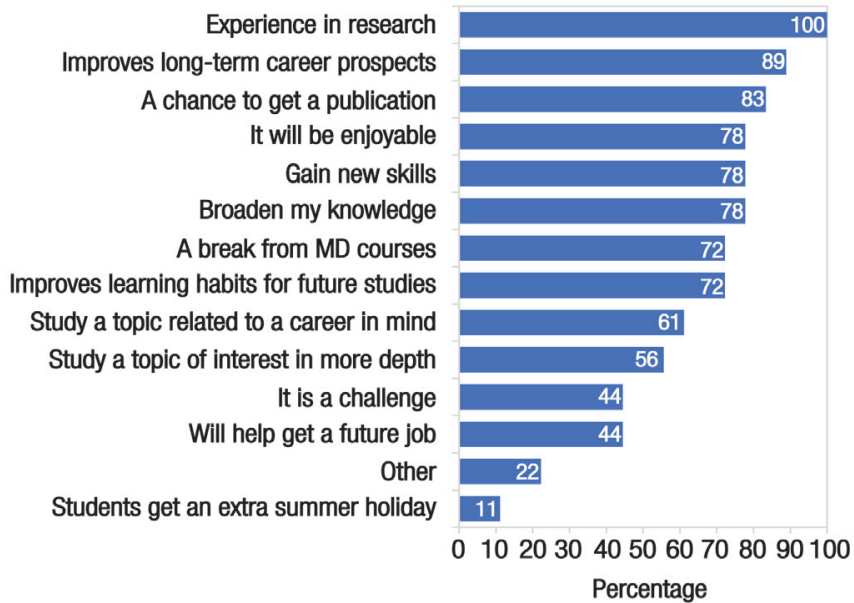

Figure 2: Motivating reasons for choosing to intercalate among medical students $(\mathrm{N}=18)$.

$M D=$ Doctor of Medicine.

be enjoyable and $72 \%$ agreed that it would improve their learning habits for future studies. Similarly, $89 \%$ of students agreed that it would improve their longterm career prospects and $44 \%$ thought it would help them to get a job in the future. Importantly, only $11 \%$ of students were motivated by an extra summer holiday [Figure 2].

The stated reasons were further studied in relation to the demographic information, MD entry path, degree choice and career ambitions. As the study included only three male students (17\%), and almost all were aged less than 23 years old and single, it was not possible to evaluate the effects of age and gender on the reasons for undertaking the intercalated phase. However, students who joined the MD programme directly were more likely to select "a chance to get a publication" as a reason for joining the programme, although this finding was not statistically significant $(P=0.06)$. Regarding other reasons, no statistically significant differences were found between students who joined the MD programme directly and those who took the foundation programme before starting the MD degree. Similarly, no statistically significant differences were observed in any reason according to the decision to intercalate and career ambitions.

To the open-ended question: "Do you feel that taking the intercalated phase will improve your thinking and reasoning skills?" all students answered affirmatively. A female student (22 years old) replied with: "Yes, I will learn how to critically appraise articles and apply them to clinical practices". Another female student (23 years old) recognised that she would improve by "solving problems of research question by improving interpretation skills". A female student (23 years old) indicated that "by building a research hypothesis and developing literature review and research skills" she would advance her thinking skills. A male student (24 years old) stated that the intercalated degree would help him "to think critically and analyse the problems and make appropriate solutions by 
identifying strategies and models". A female student (23 years old) suggested that the degree would help her "by widening the way of thinking during the discussion of different topics".

To the question: "Do you feel that taking the intercalated phase will improve your academic performance?", $44 \%$ of students indicated a belief that it would not improve their academic outcomes when returning to the MD programme, while $56 \%$ stated the opposite. Some students provided explanations for their answers; a female student (23 years old) stated that the degree would make her "more comfortable to read and understand articles and update my sources during my clinical studies". The benefit of greater learning was also expected to translate into a competitive edge in terms of knowledge as a female student (23 years old) said: "I'll be more knowledgeable on specific subjects than my colleagues". Enhanced skills were also acknowledged, for example two female students said: "It will add a value to my performance in clinical years" and it could "give me a boost how I could perform good in clinical topics" (22 and 23 years old, respectively).

Among the students who joined the intercalated phase, five students (three females and two males) chose not to continue to the MD programme and left SQU for personal reasons, having earned a BSc degree in Health Sciences.

\section{Discussion}

Little is known about factors that influence an undergraduate medical student's decision to choose to intercalate a BSc in Health Sciences within an MD degree at SQU. To the best of the researchers' knowledge, this study was the first to address this issue since the first cohort of students who received the new MD curriculum in 2008.

Intercalating an additional degree within the primary MD programme was considered a key step in the new curriculum, aiming to generate interest among undergraduate medical students in becoming clinician-scientists, thereby opting for future academic careers. Available data indicate that only a small percentage (3\%) joined the intercalated phase. It is uncertain, however, whether this small number reflects the students' lack of interest or a more global change in students' perceptions about the potential advantages of joining this phase. Hence, it is important to examine the reasoning behind students' decisions in future studies.

The current findings also suggested that a significant proportion of students decided to undertake the BSc degree due to personal interest. This observation is encouraging as it suggests motivation among students to pursue this degree with dedication. It could be also attributed to their genuine interest in or positive experience with Phase II research exposure. However, this study also revealed that the preference to intercalate was influenced by family for some students. This social pressure may have forced some students to undertake the BSc degree who had neither an interest in research nor the desire to improve their career prospects.

Interestingly, these data showed that more female students joined the intercalated phase compared to male students, with a female-to-male ratio of 5:1, although an equal number of female and male students were admitted each year into the MD programme. This finding may suggest that female students were more likely to be interested in research than male students. Another possible explanation is that female students outperform their male counterparts across all colleges at SQU and therefore have more self-belief. ${ }^{11}$ It could also be argued that an increasing number of male students take the foundation programme compared to female students. An intercalated degree would lengthen the already lengthy MD programme and may decrease their interest in obtaining an intercalated degree.

Most students in the current study choose to be academicians or have hospital-based careers. This result is consistent with earlier observations demonstrating that intercalated degrees resulted in greater interest in academic careers and hospital medical specialties. Evered et al. reported that intercalating students were more likely to enter academic careers, and this research training and experience substantially influenced their future career development. ${ }^{12}$ Similarly, Nguyen-Van-Tam et al. reported that students taking intercalated degrees showed greater interest in medical research careers and their research at this level strongly influenced the subsequent choice of specialty. ${ }^{13}$ Likewise, Goldacre et al. noted that students who undertook intercalated degrees were more likely to choose hospital medical specialties compared to those who did not pursue such a degree. ${ }^{14}$ Collectively, these observations indicate that intercalated degrees appear to develop a 'cluster' of undergraduate medical students who most likely become clinician-academicians capable of taking scientific discovery to the bedside.

This study revealed that the main reasons for intercalating were to gain experience in research and improve long-term career goals. Using a similar survey questionnaire, Agha and Howell found that the most common reasons for undergraduate students to intercalate were to improve their long-term 
career prospects and knowledge base. ${ }^{1}$ The current results are consistent with those findings, although the total number of respondents and demographic characteristics of the study populations were different. The third most common reason for intercalating in the current study was a chance to publish, although it was one of the least important reasons among students in Agha and Howell's study. ${ }^{1}$ This finding could be partially explained by the structure of the intercalated degree. In fact, in some universities, such as SQU, the degree is optional while in other universities the degree is compulsory for all students.,15 Another possible explanation could be that SQU's students recognised the benefits of having an additional qualification and associated research experiences. Additionally, they recognised that having a publication might positively impact their future academic careers. Another reason to intercalate was the perceived advantage of getting a job in the future. In fact, in many countries, intercalated degrees could help students gain points in the ranking system when applying for their first jobs as doctors. ${ }^{5}$ Surprisingly, this reason was chosen by less than half of the students in this study, suggesting a weak association between intercalating and future job competition in Omani settings.

The most suitable time to proceed with the intercalated phase is while the student has no family responsibilities. In addition, it is less likely that students who join the intercalated phase will change their major or drop-out. However, this study revealed that more than a quarter of students who chose the intercalated phase left the MD programme. This number is high when compared to Agha and Howell's study, where approximately $6 \%$ of students dropped out after intercalating. ${ }^{1}$ It should be noted that the current students were relatively young and unmarried and $60 \%$ joined the MD programme directly without taking the university's foundation programme. Further investigation is required, including in-depth interviews, to ensure a greater precision of determining the reasons behind their decisions to leave the MD programme.

Although a major strength of this study was collecting data via standardised and validated selfexplanatory measures, there were some limitations. The sample size was relatively small, which may impact the study findings. However, these results reflected the ongoing intercalated phase at SQU since its establishment in 2008. Repeating this survey in the coming years will reveal whether more students have joined the intercalated phase. Another limitation of the current study is that unrecognised confounders may affect a student's decision to intercalate, especially personal difficulties, psychological stress and parental support. Therefore, when repeating this survey, in-depth interviews should be included to better understand the effects of other factors that have not been considered in this study.

\section{Conclusion}

The findings of this study provide evidence that students who took the intercalated phase at SQU are more interested in research and want to pursue an academic career. It also shows that the intercalated BSc degree in Health Sciences forecasts the development of future clinician-scientists who are better prepared for future academic positions. Hence, further active steps should be taken to explain to the medical undergraduate students the benefits associated with the intercalated phase and help them make informed decisions about intercalating a BSc within a MD degree.

\section{CONFLICT OF INTEREST}

The authors declare no conflicts of interest.

\section{FUNDING}

No funding was received for this study.

\section{ACKNOWLEDGEMENTS}

We are grateful to all students who joined the intercalated phase. We are also thankful to all tutors involved in the BSc Heath Sciences from SQU, SQU Hospital and the College of Nursing.

\section{References}

1. Agha R, Howell S. Intercalated BSc degrees - Why do students do them? Clin Teacher 2005; 2:72-6. https://doi.org/10.1111/ j.1743-498X.2005.00059.x.

2. Mahesan N, Crichton S, Sewell H, Howell S. The effect of an intercalated BSc on subsequent academic performance. BMC Med Educ 2011; 11:76. https://doi.org/10.1186/1472-6920-11-76.

3. Nicholson JA, Cleland J, Lemon J, Galley HF. Why medical students choose not to carry out an intercalated BSc: A questionnaire study. BMC Med Educ 2010; 10:25. https://doi. org/10.1186/1472-6920-10-25.

4. Albarwani S, Al-Saadoon M, Al-Rawas O, Al-Yaarubi S, Al-Abri R, Al-Lamki L, et al. Reflections on the academic accreditation of the MD programme of the College of Medicine \& Health Sciences, Sultan Qaboos University, Oman. Sultan Qaboos Univ Med J 2014; 14:e7-e11.

5. Agha R, Fowler A, Whitehurst K, Rajmohan S, Gundogan B, Koshy K. Why apply for an intercalated research degree? Int J Surg Oncol (NY) 2017; 2:e27. https://doi.org/10.1097/IJ9.0000 000000000027

6. Jones M, Hutt P, Eastwood S, Singh S. Impact of an intercalated BSc on medical student performance and careers: A BEME systematic review: BEME Guide No. 28. Med Teach 2013; 35:e1493-510. https://doi.org/10.3109/0142159X.2013.806983.

7. Tait N, Marshall T. Is an intercalated BSc degree associated with higher marks in examinations during the clinical years? Med Educ 1995; 29:216-19. https://doi.org/10.1111/j.1365-29 23.1995.tb02833.x. 
8. Howman $M$, Jones $M$. Does undertaking an intercalated BSc influence first clinical year exam results at a London medical school? BMC Med Educ 2011; 11:6. https://doi.org/10.1186/14 72-6920-11-6.

9. McManus IC, Richards P, Winder BC. Intercalated degrees, learning styles, and career preferences: Prospective longitudinal study of UK medical students. BMJ 1999; 319:542-6. https://doi.org/10.1 136/bmj.319.7209.542.

10. Lent RW, Brown SD, Hackett G. Toward a unifying social cognitive theory of career and academic interest, choice, and performance. J Vocat Behav 1994; 45:79-122.

11. Osman MET. As females outperform male students. From: www.squ.edu.om/Portals/33/Publication/Horizon/258. pdf?ver=2014-04-27-094846-593. Accessed: Sep 2019 .
12. Evered DC, Anderson J, Griggs P, Wakeford R. The correlates of research success. Br Med J (Clin Res Ed) 1987; 295:241-6. https://doi.org/10.1136/bmj.295.6592.241.

13. Nguyen-Van-Tam JS, Logan RF, Logan SA, Mindell JS. What happens to medical students who complete an honours year in public health and epidemiology? Med Educ 2001; 35:134-6. https://doi.org/10.1046/j.1365-2923.2001.00774.x.

14. Goldacre MJ, Davidson JM, Lambert TW. Career preferences of graduate and non-graduate entrants to medical schools in the UK. Med Educ 2007; 41:349-61. https://doi.org/10.1111/ j.1365-2929.2007.02706.x

15. Collins JP, Farish S, McCalman JS, McColl GJ. A mandatory intercalated degree programme: Revitalising and enhancing academic and evidence-based medicine. Med Teach 2010; 32:e541-6. https://doi.org/10.3109/0142159X.2010.528807. 